\title{
No Genetic Differentiation of Elaphe schrenckii Subspecies in Korea Based on 9 Microsatellite Loci
}

\author{
Junghwa $\mathrm{An}^{2}$, Daesik Park ${ }^{3}$, Junghyun Lee ${ }^{4}$, Kyung-Seok Kim², \\ Hang Lee ${ }^{1,2}$ and Mi-Sook Min ${ }^{1,2, *}$ \\ ${ }^{1}$ Conservation Genome Resource Bank for Korean Wildlife (CGRB) \\ ${ }^{2}$ Research Institute for Veterinary Science, BK21 Program for Veterinary Science and College of \\ Veterinary Medicine, Seoul National University, Seoul 151-742, Korea \\ ${ }^{3}$ Division of Science Education \\ ${ }^{4}$ Department of Biology, Kangwon National University, Chuncheon 200-701, Korea
}

\begin{abstract}
The Russian ratsnake, Elaphe schrenckii, is found in Russia, China, and Korea, and is considered to be an endangered species by the Ministry of Environment in South Korea. Due to habitat loss and use in oriental medicine, their population has been severely decimated. In South Korea, two subspecies of E. schrenckii has been defined according to body color: E. s. schrenckii (blackish) and E. s. anomala (yellow-brownish). Molecular genetic studies on Elaphe schrenckii are very scarce and the taxonomy of Elaphe schrenckii subspecies is uncertain. From the present study, we attempted to identify the genetic differences of these two subspecies using species-specific microsatellites developed from the genomic library of E. schrenckii. Nine polymorphic loci were tested on 19 individuals from E. s. schrenckii $(\mathrm{n}=10)$ and E. s. anomala $(\mathrm{n}=9)$ in South Korea. The mean number of alleles was 3.78 in E. s. schrenckii and 4.11 in E. s. anomala. The average expected heterozygosity was 0.542 and 0.511 in E. s. schrenckii and E. s. anomala, respectively. We found a lack of genetic structure between two subspecies $\left(F_{\mathrm{ST}}=0.016\right)$ and no genetic discrimination between two subspecies was found. Based on the present findings by microsatellites, two subspecies can be considered as one species, E. schrenckii. However, further investigations on taxonomical status using mitochondrial and nuclear DNA sequences need to be performed and morphological \& ecological data should be revised. The genetic markers should benefit future studies of the endangered species of other Elaphe species for the study of genetic diversity and potential conservation management.
\end{abstract}

Keywords: Colubridae, Elaphe schrenckii schrenckii, Elaphe schrenckii anomala, microsatellite, genetic diversity

\section{INTRODUCTION}

The family Colubridae includes 12 subfamilies. Three of the 40-55 ratsnake species in the genus Elaphe of subfamily Colubrinae, are in South Korea: E. schrenckii, E. dione, and E. rufodorsata (National Institute of Environmental Research, 2006). The distribution of E. schrenckii habitat includes China, Russia, and Korea. Based on body color and scales on the cheek, two subspecies of E. schrenckii are recognized in South Korea: E. s. schrenckii Strauch, 1873 and E. s. anomala Boulenger, 1916. E. s. schrenckii is more blackish and E. s. anomala is brighter such as yellowish and brownish color. Although the distribution of two subspecies overlaps in regions in South Korea except for Jejudo Island, E. $s$. schrenckii is more dominant in the northern part of the Korean peninsula, whereas E. s. anomala is so in the southern part.

*To whom correspondence should be addressed

Tel: 82-2-880-1240, Fax: 82-2-888-2754

E-mail: minbio@snu.ac.kr
Among 14 known terrestrial snakes in Korea, E. schrenckii, is the largest non-venomous snake and found in barnyards and woodlands near human habituation in Korea. They mainly feed on rodents (rat, squirrel, chipmunk etc) and rarely attack bird nests. Due to their use in oriental medicine and habitat loss the E. schrenckii population has declined and has become endangered. Therefore, E. schrenckii was designated as an endangered species grade I by Ministry of Environment in South Korea and is also classified as a protected species in Russia (Zoological society of London, 2006).

Neutral genetic markers such as microsatellite have been used for studying the population genetics for various taxa (timber rattlesnake- Clark et al., 2008; western corn rootworm- Kim et al., 2008; grasshopper sparrow- Mylecraine et al., 2008; european beaver- Pelz-Serrano et al., 2009). Microsatellites contain a number of advantages making them a popular genetic marker, widely used to test ecological and evolutionary hypotheses (Zhang and Hewitt, 2003; Selkoe and Toonen, 2006). They are highly polymorphic, codomi- 
nant, relatively easy to multiplexing, and high-throughput genotyping although developing microsatellites involves considerable time and cost (Zane et al., 2002).

Several molecular studies have investigated the phylogeny of the genus Elaphe using mitochondrial markers (cytochrome $b$ and control region- Burbrink et al., 2000; cytochrome $b$ Burbrink, 2002; 12S and 16S rRNA- Heise et al., 1995; 12S rRNA and COI- Utiger et al., 2002; complete mitochondrial genome- Woo et al., 2009). Heise et al. (1995) represented the higher-level phylogeny of snakes, including Colubrids, using partial sequences from $12 \mathrm{~S}$ and $16 \mathrm{~S}$ rRNA. Colubrids were found to be paraphyletic and the associations of the genera among the Colubrids were not fully resolved with high bootstrap values. Nevertheless, sister group relationship between the genera Elaphe and Boiga was found with moderate supportive values. However, all these genetic studies have not included E. schrenckii except for the most recent study by Woo et al. (2009). Up to now, no investigations on taxonomic status and phylogeographic relationships of $E$. schrenckii and their subspecies have been completed.

Although two subspecies of E. schrenckii are acknowledged in South Korea, no genetic studies on their phylogenetic relationship have been accomplished. In the most recent article by An et al. (in press), 9 microsatellite loci were developed and characterized for E. schrenckii from South Korea, Russia and China, and E. anomala from China. Microsatellite markers are available for evaluating the extent of genetic variation. And also these markers have been extensively used to investigate genetic diversity and population structure in snakes (Manier and Arnold, 2005; Clark et al., 2008; Tzika et al., 2008). Several literatures cover the assessment of genetic diversity and differences among subspecies in various taxa using microsatellites (elk- Meredith et al., 2007; mosquitoe- Kothra et al., 2009; massasauga rattlesnakeMurphy, 2009). In this study, we sought to evaluate the genetic diversity and to determine the genetic discrimination between E. s. schrenckii and E. s. anomala using microsatellites developed from the genomic library of E. schrenckii in South Korea.

\section{MATERIALS AND METHODS}

\section{Sampling}

Nineteen tissue samples (10 E. s. schrenckii and 9 E. s. anomala) were collected from the wild all over South Korea and registered into CGRB (Conservation Genome Resource Bank for Korean Wildlife). All samples were genotyped for nine microsatellite loci. Table 1 contains the information of ID number and localities.
Table 1. Localities and ID number for two E. schrenckii subspecies in South Korea.

\begin{tabular}{cll}
\hline Taxon & ID number & \multicolumn{1}{c}{ Collection locality } \\
\hline & mms1059 & Jaecheon-si, Chungcheongbuk-do \\
& mms1073 & Incheon \\
Elaphe & mms1074 & Incheon \\
schrenckii & mms1076 & Incheon \\
schrenckii & mms1179 & Gwangju \\
& mms1184 & Busan \\
& mms1789 & Pocheon-si, Gyeonggi-do \\
& Pocheon-si, Gyeonggi-do \\
& mms1845 & Pocheon-si, Gyeonggi-do \\
& mms1052 & Jecheon-si, Gyeonggi-do \\
\hline Elaphe & Jms1053, Chungcheongbuk-do & Jecheon-si, Chungcheongbuk-do \\
schrenckii & mms1056 & Jecheon-si, Chungcheongbuk-do \\
anomala & mms1062 & Jecheon-si, Chungcheongbuk-do \\
& Jecheon-si, Chungcheongbuk-do \\
& mms1064 & Jecheon-si, Chungcheongbuk-do \\
& mms1842 & Yanggu-gun, Gangwon-do \\
& Yeongweol-gun, Gangwon-do \\
& mms1844 & Pocheon-si, Gyeonggi-do \\
\hline
\end{tabular}

\section{Methods}

DNA extraction, PCR amplification, and Genotyping

DNA from tissue samples including nine $E$. s. anomala and ten E. s. schrenckii was extracted using DNeasy blood and tissue kit (Qiagen, USA). Genotypes of 19 individuals were determined using 9 microsatellites (Es01, Es02, Es 03, Es04, Es06, Es07, Es09, Es 11 and Es 12) developed previously (An et al., in press).

PCR genotyping was performed in a $20-\mu \mathrm{L}$ reaction volume containing 40-100 ng of genomic DNA, $1 \times$ PCR buffer, $0.2 \mu \mathrm{M}$ of each primer, $2.5 \mathrm{mM}$ dNTPs, $50 \mathrm{mM} \mathrm{MgCl}_{2}$ and $1 \mathrm{U}$ of Taq polymerase. Samples were amplified in a DNA thermal cycler (Takara, Japan) programmed for denaturation at $94^{\circ} \mathrm{C}$ for $5 \mathrm{~min}$, followed by 20 cycles of $94^{\circ} \mathrm{C}$ for $40 \mathrm{sec}$, $60^{\circ} \mathrm{C}$ for $40 \mathrm{sec}$ with decrease by $0.5^{\circ} \mathrm{C}$ per cycle, $72^{\circ} \mathrm{C}$ for $40 \mathrm{sec}$, followed by 20 cycles at $94^{\circ} \mathrm{C}$ for $40 \mathrm{sec}, 50^{\circ} \mathrm{C}$ for $40 \mathrm{sec}, 72^{\circ} \mathrm{C}$ for $40 \mathrm{sec}$, and a final extension at $72^{\circ} \mathrm{C}$ for 10 min. PCR products were sized on ABI3730xl DNA Analyser (ABI, USA) alongside GeneScan 500 Rox size standard using GeneMapper software v.4.0.

\section{Data analysis}

The number of alleles, range of product size, observed heterozygosity $\left(H_{\mathrm{o}}\right)$, expected heterozygosity $\left(H_{\mathrm{e}}\right)$, polymorphic information content (PIC), and $P$-value were calculated for each locus and each subspecies using CERVUS v.3.0 (Kalinowski et al., 2007). Departures from Hardy-Weinberg equilibrium at each locus and linkage disequilibrium between loci were tested using Genepop v.3.4 (Raymond and Rousset, 
Table 2. Characteristics of the nine microsatellite loci optimized for E. schrenckii. Locus name, clone ID, sample size (N), number of alleles per locus $(\mathrm{k})$, observed $\left(H_{0}\right)$ and expected $\left(H_{\mathrm{e}}\right)$ heterozygosities, PIC (polymorphic information content), and $P$-value are reported.

\begin{tabular}{|c|c|c|c|c|c|c|c|c|c|}
\hline Locus & Clone ID & Taxon & $\mathrm{N}$ & $\mathrm{k}$ & Size & $H_{\circ}$ & $H_{\mathrm{e}}$ & PIC & $P$-value \\
\hline \multirow{2}{*}{ Es01 } & \multirow{2}{*}{ AF2 } & E. s. schrenckii & 9 & 6 & $203-235$ & 0.222 & 0.753 & 0.763 & 0.586 \\
\hline & & E. s. anomala & 8 & 4 & $225-239$ & 0.375 & 0.484 & 0.544 & $0.000 *$ \\
\hline \multirow{2}{*}{ Es02 } & \multirow{2}{*}{$\mathrm{AC2}$} & E. s. schrenckii & 10 & 5 & $114-132$ & 0.700 & 0.660 & 0.611 & 0.205 \\
\hline & & E. s. anomala & 9 & 5 & $110-130$ & 0.556 & 0.735 & 0.690 & 0.206 \\
\hline \multirow{2}{*}{ Es03 } & \multirow{2}{*}{ AF8 } & E. s. schrenckii & 9 & 5 & $223-267$ & 0.333 & 0.698 & 0.710 & 0.289 \\
\hline & & E. s. anomala & 8 & 7 & $223-263$ & 0.875 & 0.766 & 0.779 & 0.010 \\
\hline \multirow{2}{*}{ Es04 } & \multirow{2}{*}{ AA2 } & E. s. schrenckii & 10 & 4 & $198-222$ & 0.700 & 0.575 & 0.526 & 0.155 \\
\hline & & E. s. anomala & 9 & 4 & $198-222$ & 0.444 & 0.512 & 0.473 & 0.433 \\
\hline \multirow{2}{*}{ Es06 } & \multirow{2}{*}{ AF9 } & E. s. schrenckii & 10 & 3 & $206-220$ & 0.200 & 0.540 & 0.466 & 0.002 \\
\hline & & E. s. anomala & 9 & 3 & $206-220$ & 0.556 & 0.660 & 0.586 & 0.002 \\
\hline \multirow{2}{*}{ Es07 } & \multirow{2}{*}{$\mathrm{BC} 11$} & E. s. schrenckii & 9 & 3 & $165-174$ & 0.111 & 0.438 & 0.498 & 1.000 \\
\hline & & E. s. anomala & 9 & 3 & $165-174$ & 0.222 & 0.204 & 0.194 & 0.012 \\
\hline \multirow{2}{*}{ Es09 } & \multirow{2}{*}{$\mathrm{BH} 6$} & E. s. schrenckii & 10 & 2 & $245-247$ & 0.400 & 0.420 & 0.332 & 1.000 \\
\hline & & E. s. anomala & 9 & 2 & $245-247$ & 0.333 & 0.401 & 0.321 & 1.000 \\
\hline \multirow{2}{*}{ Es11 } & \multirow{2}{*}{$\mathrm{CC} 2$} & E. s. schrenckii & 9 & 1 & 164 & 0.000 & 0.000 & 0.164 & - \\
\hline & & E. s. anomala & 9 & 1 & 164 & 0.000 & 0.000 & 0.000 & - \\
\hline \multirow{2}{*}{ Es12 } & \multirow{2}{*}{ CC5 } & E. s. schrenckii & 10 & 5 & $178-200$ & 0.600 & 0.790 & 0.756 & 0.019 \\
\hline & & E. s. anomala & 8 & 8 & $170-194$ & 0.500 & 0.836 & 0.908 & 0.018 \\
\hline
\end{tabular}

*Locus not in Hardy-Weinberg equilibrium $(P<0.05)$.

1995). Genetic differentiation between two E. schrenckii subspecies based on pairwise $F_{\mathrm{ST}}$ was estimated using ARLEQUIN v.3.1 (Excoffier et al., 2005).

\section{RESULTS AND DISCUSSION}

Molecular genetic markers can provide valuable insights into the geographical distribution of genetic diversity of species. Most of wildlife including mammals, birds, amphibians, reptiles, and so on is considered to be endangered or threatened because of illegal hunting, oriental medicine, habitat destruction. Especially, natural population of snakes in reptiles constantly declined, mainly because of predation by introduced species, human persecution, and habitat destruction (Tzika et al., 2008). A comprehensive assessment of population structure is one critical component for their effective conservation. To establish long term conservation strategy, it is worthwhile to take account for genetic approach.

Here, we used nuclear microsatellites developed from genomic DNA library of E. schrenckii from South Korea. Among the newly developed 10 loci, nine were selected for this study. Characteristics of the nine microsatellite loci for each subspecies assessed are shown in Table 2. In total, 49 alleles for the nine loci were identified in both subspecies. The number of alleles ranged from one to eight per locus in E. s. anomala and one to six per locus in E. s. schrenckii.
Average expected heterozygosities were $0.511(0.000-0.836)$ in E. s. anomala and $0.542(0.000-0.790)$ in E. s. schrenckii. $H_{\mathrm{o}}$ was rather low compared to $H_{\mathrm{e}}$, an average of 0.429 (0.000-0.875) in E. s. anomala and a mean of $0.363(0.000$ $0.700)$ in $E$. s. schrenckii. No significant differentiation in genetic diversity was found between the two subspecies. Mean $H_{\mathrm{e}}$ calculated from E. goydi was 0.53 which is compatible with the values of $E$. shcrenckii subspecies but is rather small than other snakes (0.59 in timber rattlesnakes, Clark et al., 2008; 0.64 in jamaican boa, Tzika et al., 2008).

In addition, we tested for deviation from Hardy-Weinberg equilibrium using the HW exact test and the Markov chain method for $P$-value estimation (Guo and Thompson, 1992). Only one locus in E. s. anomala population, Es01, was significantly deviated from HWE after a sequential Bonferroni correction ( $\alpha=0.05, P>0.05$; Rice, 1989) because of a deficiency of heterozygotes, which might be due to the Wahlund effect (Templeton, 2006). No significant linkage disequilibrium between loci across two subspecies was observed.

$F_{\mathrm{ST}}$ between the two subspecies was 0.016 and genetic differentiation was not significant $(P>0.05)$ between two subspecies at all loci. Within the species, genetic differentiation on the basis of $F_{\mathrm{ST}}$ value could be identified. Tzika et al. (2008) reported that the $F_{\mathrm{ST}}$ value of three populations for jamaican boa (Epicrates subflavus) was $0.093(P<0.001)$. Among 5 populations of timber rattlesnake (Crotalus horri$d u s$ ), $F_{\mathrm{ST}}$ values were ranged from 0.000 to 0.005 (Clark et 
al., 2008). Compared to other results, the value of $F_{\mathrm{ST}}$ between the two subspecies, E. s. schrenckii and E. s. anomala, was generally lower than others and indicating no genetic discrimination $\left(F_{\mathrm{ST}}=0.016, P>0.005\right)$.

In addition, no distinctive clusters by the STRUCTURE analysis were detected. Both $F_{\text {ST }}$ statistics and STRUCTURE analysis indicate no genetic discrimination between $E$. $s$. schrenckii and E. s. anomala in South Korea. E. s. schrenckii and E. s. anomala have either sympatric or parapatric distribution in South Korea, indicating that they might be considered as the same species with different individual color variation (Park, 2010). Similar findings of low genetic differentiation among subspecies were shown in two literatures. Palo et al. (2001) found that low differentiation was detected between Baltic seal (Phoca hispida botnica) and Arctic seal (P. h. hispida) at eight microsatellite loci, implying the possibility of the same species. In addition, no significant differentiation of morphological characters between two subspecies was identified (Park, 2010). Further investigations of the taxonomic status of E. schrenckii from Russia, China, and Korea need to be confirmed using mitochondrial and nuclear DNA sequences, as well as morphological taxonomy including E. schrenckii from Russia and ecological data. To conclude, genetic markers including species-specific microsatellites, DNA sequences will be helpful tools for population genetic and ecological studies of the endangered ratsnakes and related other Elaphe species.

\section{ACKNOWLEDGEMENTS}

The authors would like to thank Eu-Jin Cheong for help with her assistance with PCR and genotyping. This work was supported by a Korea Science and Engineering Foundation (KOSEF) grant funded by the Korean government (MOST) (R01-2007-000-20955-0) and by the Korean Ministry of Environment as "The Eco-technopia 21 project(\#052-091080)".

\section{REFERENCES}

Burbrink, F., R. Lawson and J. Slowinski, 2000. Mitochondrial DNA phylogeography of the polytypic north American rat snake (Elaphe obsolete): a critique of the subspecies concept. Evolution, 54(6): 2107-2118.

Burbrink, F., 2002. Phylogeographic analysis of the cornsnake (Elaphe guttata) complex as inferred from maximum likelihood and Bayesian analyses. Mol. Phylogenet. Evol., 25: 465-476.

Clark, R., W. Brown, R. Stecher and K. Zamudio, 2008. Integrating individual behavior and landscape genetics: the popula- tion structure of timber rattlesnake hibernacula. Mol. Ecol., 17: 719-730.

Dallas, J., F. Marshall, S. Piertney, P. Bacon and P. Racey, 2002. Spatially restricted gene flow and reduced microsatellite polymorphism in the Eurasian otter Lutra lutra in Britain. Con. Genet., 3: 15-28.

Excoffier, L., G. Laval and S. Schneider, 2005. Arlequin ver. 3.0: an integrated software package for population genetics data analysis. Evol. Bioinfo. Online, 1: 47-50.

Guo, S. and E. Thompson, 1992. Performing the exact test of Hardy-Weinberg proportions for multiple alleles. Biometrics, 48: 361-372.

Heise, P., L. Maxson, H. Dowling and S. Hedges, 1995. Higherlevel snake phylogeny inferred from mitochondrial DNA sequences of $12 \mathrm{~S}$ rRNA and 16S rRNA genes. Mol. Biol. Evol., 12(2): 259-265.

Kalinowski, S., M. Taper and T. Marshall, 2007. Revising how the computer program CERVUS accommodates genotyping error increases success in paternity assignment. Mol. Ecol., 16: 1099-1006.

Kim, K., S.U. Stolz, N. Miller, E. Waits, T. Guillemaud, D. Suerford and T. Sappington, 2008. A core set of microsatellite markers for western corn rootworm (Coleoptera: Chrysomelidae) population genetics studies. Envion. Entomol., 37(2): 293-300.

Kothera, L., E.M. Zimmerman, C.M. Richards and H.M. Savage, 2009. Microsatellite characterization of subspecies and their hybrids in Culex pipiens complex (Diptera: Culicidae) mosquitoes along a north-south transect in the central united states. J. Med. Entomol., 46(2): 236-248.

Manier, M. and S. Arnold, 2005. Population genetic analysis identifies source-sink dynamics for two sympatric garter snake species (Thamnophis elegans and Thamnophis sirtalis). Mol. Ecol., 14: 3965-3976.

Meredith, E.P., J.A. Rodzen, J.D. Banks, R. Schaefer, H.B. Ernest, T.R. Famula and B.P. May, 2007. Microsatellite analysis of three subspecies of elk (Cervus elaphus) in California. J. Mammalogy, 88(3): 801-808.

Murphy, M.J., 2009. Using microsatellite DNA to genetically identify a potential hybrid population of endangered massasauga rattlesnakes (Sistrurus catenatus) in north central Missouri. PhD Thesis. Ohio State Univ., pp. 1-24.

Mylecrain, K., N. Bulgin, H. Gibbs, P. Vickery and D. Perkins, 2008. Limited genetic structure and evidence for dispersal among populations of the endangered Florida grasshopper sparrow, Ammodramus savannarum floridanus. Conserv. Genet., 9: 1633-1638.

National Institute of Environmental Research in South Korea, 2006. Guidelines of the third national ecosystem survey, $p$. 189.

Palo, J., H. Makinen, E. Helle, O. Stenman and R. Vainola, 2001. Microsatellite variation in ringed seals (Phoca hispida): genetic structure and history of the Baltic sea population. Hered., 86: 609-617.

Park, D., 2010. Annual report of developing standard rearing 
protocols of endangered endemic reptiles and the study of their basic ecology. Kangwon National University, pp. 10-61.

Pelz-Serrano, K., A. Munguia-Vega, A. Piaggio, M. Neubaum, P. Munclinger, A. Partl, C. Riper and M. Culver, 2009. Development of nine new microsatellite loci for the American beaver, Castor Canadensis (Rodentia: Castoridae), and cross-species amplification in the European beaver, Castor fiber. Mol. Ecol. Res., 9: 551-554.

Raymond, M. and F. Rousset, 1995. GENEPOP v3.2: population genetics software for exact tests and ecumenicism. J. Hered., 86: 248-249.

Rice, W., 1989. Analyzing tables of statistical tests. Evolution, 43: 223-225.

Selkoe, A. and T. Robert. 2006. Microsatellites for ecologists: a practical guide to using and evaluating microsatellite markers. Ecology Letters, 9: 615-629.

Templeton, A., 2006. Population genetics and microevolutionary theory. John Wiley \& Sons, New Jersey.

Tzika, A., S. Koenig, R. Miller, G. Garcia and M. Milinkovitch, 2008. Population structure of an endemic vulnerable species, the Jamaican boa (Epicrates subflavus). Mol. Ecol., 17: 533-
544.

Utiger, U., N. Helfenberger, B. Schatti, C. Schmidt, M. Ruf and V. Ziswiler, 2002. Molecular systematic and phylogeny of old and new world ratsnakes, Elaphe AUCT., and related genera (Reptilia, Squamata, Colubridae). Rus. J. Herpetol., 9(2): 105-124.

Woo, H., S. Ryu, K. Jang, E. Choi, S. Kim and U. Hwang, 2009. Mitochondrial genome of the Korean colubrid snake Elaphe schrenckii (Reptilla; Squamata; Colubridae). Mitochondrial DNA, 20(5-6): 107-109.

Zane, L., L. Bargelloni and T. Patarnello, 2002. Strategies for microsatellite isolation: a review. Mol. Ecol., 11: 1-16.

Zhang, D.X. and G.M. Hewitt, 2003. Nuclear DNA analyses in genetic studies of population: practice, problems and prospects. Mol. Ecol., 12: 563-584.

Zoological society of London, 2006. Mongolian Red List of Reptiles and Amphibians. Regent's Park, London.

Received February 19, 2010 Accepted March 11, 2010 